ORIGINAL ARTICLE

\title{
The association between occupational factors and adverse health outcomes in chronic obstructive pulmonary disease
}

\author{
P D Blanc, M D Eisner, L Trupin, E H Yelin, P P Katz, J R Balmes
}

Occup Environ Med 2004;61:661-667. doi: 10.1136/oem.2003.010058

See end of article for authors' affiliations ....................

Correspondence to: Dr P Blanc, Division of Occupational and Environmental Medicine, University of California San Francisco, 350 Parnassus Avenue, Suite 609, San Francisco, CA 94117, USA: blancp@itsa.ucsf.edu

Accepted 29 January 2004

\begin{abstract}
Background and Aims: Despite recognition that occupational exposures may make a substantive contribution to the aetiology of COPD, little is known about the potential role of work related factors in COPD related health outcomes.

Methods: Prospective cohort study using structured telephone interviews among a random sample of adults aged 55-75 reporting a COPD condition (emphysema, chronic bronchitis, or COPD). Using multivariate models adjusting for smoking and demographic factors, the separate and combined associations were estimated between occupational exposure to vapours, gas, dust, or fumes (VGDF) and leaving work due to lung disease (respiratory related work disability) with health outcomes and utilisation ascertained at one year follow up.

Results: Of 234 subjects, 128 (55\%) reported exposure to VGDF on their longest held jobs, 58 (25\%) reported respiratory related work disability, and 38 (16\%) subjects reported both. Combined exposure to VGDF and respiratory related work disability (rather than either factor alone) was associated with the greatest risk at follow up of frequent (everyday) restricted activity days attributed to a breathing or lung condition (OR 3.8; 95\% Cl 1.4 to 10.1), emergency department (ED) visit (OR 3.9; $95 \% \mathrm{Cl} 1.4$ to 10.5), and hospitalisation (OR 7.6; $95 \% \mathrm{Cl} 1.8$ to 32 ).

Conclusions: Among persons with COPD, past occupational exposures and work disability attributed to lung disease, particularly in combination, appear to be risk factors for adverse health related outcomes.
\end{abstract}

$\mathrm{T}$ here is growing recognition that occupational exposures may make a substantive contribution to the aetiology of chronic bronchitis, emphysema, and airway obstruction, even after taking into account the known impact of cigarette smoking on such disease. ${ }^{12}$ A recent report of the American Thoracic Society estimated that $15 \%$ of all cases within this group of clinical conditions, subsumed under the broader rubric of chronic obstructive pulmonary disease (COPD), can be attributed to occupational exposures. ${ }^{3}$

Very little is known, however, about the potential role that occupational factors may play in affecting the outcomes of COPD once disease is established. By analogy to asthma, another obstructive lung disease with an important occupational component, there are ample data indicating that work related risk factors can be linked to certain adverse outcomes. For example, work disability is a common problem in adult asthma generally, ${ }^{4}$ but is far more prominent among persons whose disease onset is related to occupational exposures. ${ }^{5}$ There are also data suggesting that those with occupationally related asthma may manifest increased disease severity and healthcare utilisation. ${ }^{6}$

We studied the potential impact of occupational factors on health outcomes in a prospective cohort of adults with COPD. In a previous cross-sectional analysis of this cohort, we found that occupational exposures in the longest held job accounted for $9-20 \%$ of COPD prevalence. ${ }^{7}$ In the current prospective study, based on one year follow up in that cohort, we analyse the potential role of work related factors as risk factors for respiratory symptoms, restricted activity, disease specific quality of life, and healthcare utilisation.

\section{METHODS}

\section{Overview}

In a prospective cohort study, we carried out baseline and one year follow up structured telephone interviews among 234 adults aged 55-75 years who reported a physician's diagnosis of emphysema, chronic bronchitis, or COPD (the study definition of COPD conditions) in the initial interview. Subjects were recruited by random digit dialling within the contiguous 48 US states, with over-sampling in geographic areas with higher COPD mortality. We used these data to estimate the impact of occupational factors on respiratory symptoms, restricted activity, general health status, disease specific quality of life, and healthcare utilisation. The UCSF Committee on Human Research approved the study.

\section{Subject recruitment}

The methods of the baseline study have been published previously. ${ }^{7}$ In the initial recruitment, which took place in 2001,383 adults with COPD were interviewed as part of a larger cohort of 2114 US adults identified by random digit telephone dialling. The sampling frames included both a US nationwide sample (contiguous 48 states) and a sample drawn from geographic "hot spot" regions with increased COPD mortality. ${ }^{8}$ As part of the "hot spot" sampling, additional subjects were recruited for whom participation eligibility was limited to the presence of lung disease, thus enriching the overall sample further for cases of COPD. For all participants, the age at recruitment was limited to 55-75 years. The participation rate at baseline was 53\% among households meeting an initial brief eligibility screening.

\section{Follow up recruitment and analysis}

Approximately 12 months after initial interview, we attempted to re-contact a subset of baseline interviewees. Figure 1 shows the follow up subject flow. The potential follow up group included all subjects who reported either COPD or asthma at baseline $(n=517)$. Of these, 61 stated at

Abbreviations: COPD, chronic obstructive pulmonary disease; VGDF, vapours, gas, dust, or fumes; $\mathrm{ED}$, emergency department; $\mathrm{Cl}$, confidence interval; AQ20, Airways Questionnaire 20; QOL, quality of life 


\section{Main messages}

- Work disability in COPD is common.

- Past work exposures are linked to risk of work disability.

- Past exposure and work disability are each predictors of poorer health status and QOL.

- Past exposure and work disability together predict greater risk of healthcare utilisation.

the completion of their baseline study interview that they did not wish to be contacted again. The remaining subjects were sent letters informing them that they would be re-contacted by the study team. This included mail-back postcards providing an opportunity to forgo participation. There were 34 persons who declined by this route and an additional 18 who declined at the time of the actual follow up telephone contact. Of the 404 remaining in the potential subject pool, 44 could not be located and eight deaths were reported. In all, 352 subjects were re-interviewed, which corresponds to $69 \%$ of those presumed alive at follow up overall.

We limited the main analyses presented here to 267 subjects with COPD (69\% of 386 interviewed at baseline), excluding 85 subjects who reported asthma, but not chronic bronchitis, emphysema, or COPD. Table l compares the characteristics of re-interviewed subjects with COPD compared to those with COPD who were not re-interviewed. There were no statistical differences by follow up status. Including those with asthma in the analysis by follow up status similarly did not reveal substantive selection effects (data not shown). Because we were specifically interested in work disability factors, we further limited analysis to those with a history of labour force participation (25 subjects had never held any salaried employment). There were 12 additional subjects excluded because of key missing variables, leaving a final study group of 234 subjects.

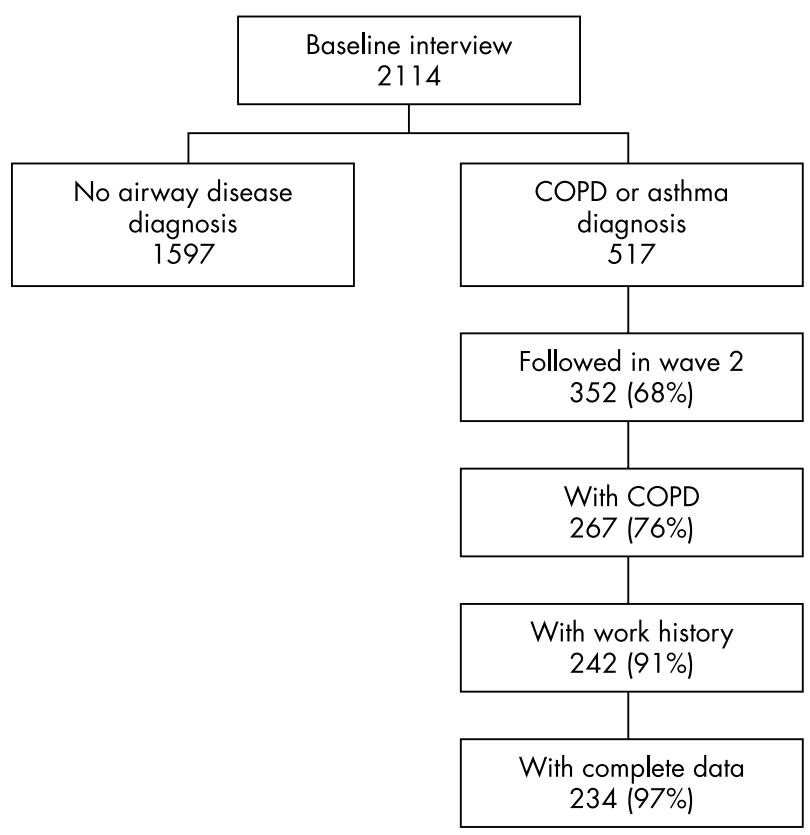

Figure 1 Flow of subject recruitment among 2114 subjects interviewed at baseline.
Policy implications

- The occupational burden of COPD (including potential costs) includes impact of disease severity.

- Prevention of COPD morbidity should take work factors into account.

\section{Study interviews}

The baseline and follow up subject interviews were similar. Interviews were conducted by telephone by trained interviewers (Field Research Corporation, San Francisco, California). Structured survey items were administered using computer assisted telephoning interviewing (CATI) software. The baseline and follow up surveys addressed respiratory symptoms and medications; co-morbid conditions and general health status; healthcare utilisation; smoking status; and demographic and socioeconomic factors.

We used the baseline survey to establish the respiratory status of the respondent, based on self report of a physician diagnosis of chronic bronchitis, emphysema, COPD, or asthma. The baseline survey also included an extensive battery eliciting employment information, including current or most recent job as well as the longest held job. Open ended items covering occupation and industry of employment were later classified according to US 2000 Census codes. ${ }^{9}$ We ascertained occupational exposure to vapours, gas, dust, or fumes on the longest held job using a questionnaire item developed for the European Community Respiratory Health Survey, ${ }^{10}$ and by means of a job exposure matrix which categorised jobs into high, intermediate, or low risk of dust exposure. ${ }^{11}$ Those not working at the time of the baseline interview were also asked if this was due, at least in part, to a "lung or breathing condition", which we used to define "respiratory related work disability". The follow up survey omitted repetitious items on past employment and demographic characteristics. We added a new battery assessing quality of life (see below), along with other items related to functional status and health.

\section{Definition of COPD}

We used a standard epidemiological definition of COPD based on report of a physician's diagnosis of chronic bronchitis, emphysema, or, specifically, "COPD". ${ }^{12}$ The COPD classification allowed inclusion of respondents who also reported concomitant asthma, but subjects with asthma alone were excluded from this analysis as noted above. We also developed an alternative, narrower definition of COPD for sensitivity analyses that included only subjects reporting emphysema or COPD, excluding those with chronic bronchitis alone.

\section{Health outcomes: symptoms and activity limitations}

Respondents were asked to quantify their respiratory symptoms over the 14 days preceding the interview in two ways. First, shortness of breath on exertion was graded as none, walking at a rapid pace, walking at the standard pace of others, or when walking even at one's own pace. Second, the frequency that breathing was bothered (days or nights) was quantified as no days, some or most days, or everyday. In addition to these measures, we also developed a measure of decline in respiratory status as an increase in reported level of shortness of breath or bothered breathing at follow up compared to baseline. We ascertained daily activity restriction using a questionnaire item adapted from the National Health Interview Survey. ${ }^{13}$ Specifically, this item asked respondents to indicate how many days their activity was 
Table 1 Baseline characteristics of 386 subjects with COPD by follow up status

\begin{tabular}{|c|c|c|c|c|c|c|c|}
\hline \multirow[b]{2}{*}{ Characteristic at baseline } & \multicolumn{2}{|c|}{$\begin{array}{l}\text { All } \\
(n=386)\end{array}$} & \multicolumn{2}{|c|}{$\begin{array}{l}\text { Re-interviewed } \\
(n=267)\end{array}$} & \multicolumn{2}{|c|}{$\begin{array}{l}\text { Not interviewed } \\
(n=119)\end{array}$} & \multirow[b]{2}{*}{$p$ value } \\
\hline & $\mathbf{n}$ & $\%$ & $n$ & $\%$ & $\mathbf{n}$ & $\%$ & \\
\hline Age range (years) & & & & & & & 0.59 \\
\hline $55-59$ & 111 & 29 & 74 & 28 & 37 & 31 & \\
\hline $60-64$ & 100 & 26 & 73 & 27 & 27 & 23 & \\
\hline $65-75$ & 175 & 45 & 120 & 45 & 55 & 46 & \\
\hline Female & 246 & 64 & 168 & 63 & 78 & 66 & 0.62 \\
\hline White, non-Hispanic & 332 & 86 & 230 & 86 & 102 & 86 & 0.91 \\
\hline Highest educational level & & & & & & & 0.92 \\
\hline High school or less & 204 & 53 & 142 & 53 & 62 & 53 & \\
\hline Some college & 105 & 27 & 74 & 28 & 31 & 27 & \\
\hline College graduate or above & 74 & 19 & 50 & 19 & 24 & 21 & \\
\hline Annual household income & & & & & & & 0.49 \\
\hline$<\$ 20000$ & 144 & 44 & 107 & 44 & 37 & 42 & \\
\hline$\$ 20000-40000$ & 108 & 33 & 80 & 33 & 28 & 31 & \\
\hline$>\$ 40-000$ & 79 & 24 & 55 & 23 & 24 & 27 & \\
\hline Chronic bronchitis alone & 194 & 50 & 132 & 49 & 62 & 52 & 0.63 \\
\hline Cigarette smoking status & & & & & & & 0.39 \\
\hline Never & 75 & 19 & 48 & 18 & 27 & 23 & \\
\hline Former & 127 & 33 & 86 & 32 & 41 & 34 & \\
\hline Current & 184 & 48 & 133 & 50 & 51 & 43 & \\
\hline Ever employed & 352 & 91 & 242 & 91 & 110 & 92 & 0.56 \\
\hline Exposure to VGDF* & 185 & 54 & 128 & 55 & 57 & 53 & 0.75 \\
\hline Exposure by job matrix* & & & & & & & 0.94 \\
\hline Intermediate exposure & 94 & 27 & 64 & 27 & 30 & 28 & \\
\hline High exposure risk & 36 & 11 & 25 & 11 & 11 & 10 & \\
\hline Left work due to lung disease ${ }^{*}$ & 79 & 23 & 58 & 25 & 21 & 19 & 0.28 \\
\hline
\end{tabular}

VGDF, vapours, gas, dusts, or fume reported at baseline on longest held employment.

*Includes subjects with a history of labour force participation and values for all key study variables ( $n=234$ for re-interviewed cohort; $n=108$ of those not reinterviewed).

Total for income $(n=331)$ and education $(n=383)$ reflects missing responses to these items.

limited due to a respiratory condition during the past month. Based on the frequency distribution of reported limitation, we categorised responses as no restricted days at all, some or most days (1-29 days), or every day (30-31 days).

\section{Health outcomes: general health status and COPD specific QOL}

We assessed physical and mental health status using the SF12 physical component summary (PCS) and mental component summary (MCS) scores. The SF-12 is derived from the Medical Outcomes Study SF-36 instrument and is a widely used measure of generic health status. ${ }^{14}{ }^{15}$ The PCS and MCS scores reflect the overall dimensions of physical and mental health status, respectively. Neither is condition specific, but both have been used to assess health status in populations with chronic lung disease. ${ }^{16}{ }^{17}$ Higher SF-12 PCS and MCS scores reflect more favourable health states. We used an established algorithm to impute any single missing values within the battery. ${ }^{18} 19$

In order to measure disease specific quality of life (QOL), we used a validated 20 item instrument, the Airways Questionnaire 20 (AQ20) that has been developed from the longer St George's Respiratory Questionnaire. ${ }^{2021}$ The AQ20 is designed to evaluate functional and psychological aspects of QOL among persons with COPD or asthma, and has been shown to correlate with other respiratory disease specific instruments measuring domains such as activity limitations, dyspnoea, emotional status, and mastery of disease.

We modified this 20 item instrument to allow response categories for six of the items to take into account the possibility that certain key physical activities queried might not be done specifically because of respiratory limitations (for example, gardening). ${ }^{22}$ For those items, disability was counted as a response contributing to a poorer (higher numeric) QOL score.

\section{Data analysis}

We compared the characteristics of respondents by follow up status using the $\chi^{2}$ test for trend (education and income), the $\chi^{2}$ test (all other categorical variables), or Student's $t$ test (continuous variables).

We hypothesised that occupational factors could lead to adverse health outcomes in COPD through several pathways. Occupational exposure to VGDF was a key risk factor of study interest. We wished to ascertain whether COPD outcomes were worse among the subset of persons with past VGDF exposure, given its association with COPD prevalence in our previous cross-sectional study. ${ }^{7}$ We also wished to test whether an alternative measure of adverse working conditions, based on a job exposure matrix linked to longest held occupation would similarly predict COPD outcomes.

In addition to relations between job exposures and health outcomes, we hypothesised that respiratory related work disability reported at baseline would be associated with increased risk of adverse outcomes at follow up. We posited that persons impaired from COPD while still of working age are likely to have disease of greater severity, with earlier onset and more rapid progression, compared to others with the condition. We recognised, however, that VGDF (or high risk occupations based on a job exposure matrix) might in itself be a risk factor for respiratory related work disability, a relation that has been observed previously. ${ }^{4}$ Thus our analysis needed to take into account that exposure to VGDF could serve as a risk factor for adverse outcomes through two pathways: by virtue of being linked to respiratory related work disability or by leading to adverse outcomes independent of antecedent work disability. The analysis also needed to assess the association of respiratory related work disability independent of occupational VGDF exposure.

We tested the hypothesised relation at baseline between VGDF as the independent variable and respiratory related work disability as the dependent variable using multiple logistic regression, adjusted for smoking and demographic 
variables. As a sensitivity analysis we re-estimated the same model, substituting exposure based on the job exposure matrix for reported VGDF exposure.

In the next analyses, we used multiple linear regression analysis to study three outcomes ascertained at follow up. These were: SF-12 PCS, SF-12 MCS, and QOL score. The independent predictors in these models, consistent with our hypothesised model and the findings in the logistic regression analysis described above, were: past exposure to VGDF without reported respiratory related work disability; past exposure to VGDF combined with respiratory related work disability, and respiratory related work disability alone.

This analytical framework allowed us to test a model in which VGDF might act on health outcomes independently of respiratory related work disability, respiratory related work disability might act independently of VGDF, or both might act together. These models also included smoking status, age, gender, and race. We did not include in these models measures of socioeconomic status, such as household income or education, because of the correlations among occupational status and such variables.

As an additional analysis to further delineate the interrelationships among work exposure, respiratory related work disability and key outcomes, we retested the association between exposure to VGDF and SF-12 PCS and QOL stratified by the presence or absence of respiratory related work disability. Because of relatively small numbers in the stratified analysis, we did not include other covariates in these models.

We used logistic regression analysis in a similar approach to estimate the relations among the same independent variables and three other categorical outcomes ascertained at follow up interview. These were: restricted activity breathing (defined as restricted activity specifically attributed to a lung or breathing problem every day compared to some or no days in the past month), and one or more emergency department (ED) visit or one or more hospitalisations for a respiratory condition in the past year. For these analyses we tested two hierarchical models. The first model tested either VGDF or respiratory related work disability separately, without the other predictor variable in the model (although including other covariates). The second level model included both VGDF and respiratory related work disability in the same model.

We used a similar approach to estimate the risk for decline in respiratory status (increasing dyspnoea since baseline; excluding subjects with maximal dyspnoea at baseline, $\mathrm{n}=75$ ) and risk of incident ED visit or hospitalisation (excluding subjects reporting such utilisation in the baseline year, $n=48$ ). Because this was a key test of the interrelationships of occupational exposure and work disability, we repeated this analysis substituting self reported VGDF exposure with exposure based on the job exposure matrix.

In order to evaluate the sensitivity of our findings to our epidemiological definition of COPD, we repeated several of the key analyses excluding subjects who reported chronic bronchitis alone without either concomitant emphysema or COPD $(n=112)$. All statistical analyses used SAS (Cary, NC).

\section{RESULTS}

Among the 234 subjects analysed, 128 (55\%) reported exposure to vapours, gas, dust, or fumes (VGDF) on their longest held jobs in their baseline interviews. There were 89 $(38 \%)$ with either intermediate or high exposure risk occupations based on a job exposure matrix classification. Fifty eight (25\%) reported that they had left work altogether due to their lung disease (respiratory related work disability). Of these, 38 (16\%) reported both work exposure to VGDF and respiratory related work disability.
Table 2 presents the frequencies for various measures of health status and healthcare utilisation ascertained at follow up among the 234 subjects analysed. Overall, the group reported a range of morbidity. "Bothered breathing" was reported every day or night (whichever was more frequent) by one in four subjects, with a similar frequency of dyspnoea with minimal exertion. Altogether, $30 \%$ of subjects reported at least some restricted activity attributed to breathing (restricted activity breathing). The mean SF-12 PCS score of $36(12) \%$ represents a substantive decrement relative to a value of 45 , the approximate age related population norm. ${ }^{14}$ The reported one year frequency of healthcare utilisation for lung disease was 15\% for ED visit and 10\% for hospitalisation.

Exposure to VGDF was associated with respiratory related work disability (OR 1.9; 95\% CI 1.0 to 3.6), taking into account smoking status, age, gender, and race. Among covariates, the strongest association with respiratory related work disability was for former smoking (OR 4.2; 95\% CI 1.3 to 13.1). Current smoking was also associated with respiratory related work disability (OR 2.8; 95\% CI 0.8 to 9.2 ).

Reanalysing the same model substituting for VGDF an exposure classification based on a job matrix showed that intermediate or high risk occupations combined (relative to low risk jobs) were associated with an increased point estimate of the risk of disability (OR 1.6; 95\% CI 0.8 to 3.0 ), although this did not exclude the no-effect level.

Both prior work exposure to VGDF and respiratory related work disability were associated with significantly lower SF12 PCS values and significantly poorer QOL, adjusting for smoking status and demographics (table 3). This effect was shown by both risk factors individually as well as concurrently. There was a gradient of effect in relation to both SF-12 PCS and QOL scores. In contrast, neither VGDF nor respiratory related work disability were predictors of SF-12 MCS score.

Among those without respiratory related work disability $(\mathrm{n}=176)$, exposure to VGDF was related to both SF-12 PCS $(\beta=-3.9(1.8) ; p=0.03)$ and QOL $(\beta=1.8(0.7) ; p=0.01)$. In contrast, among those who had experienced respiratory related work disability $(n=58)$ VGDF was not associated with incrementally worse health status measured by the

\begin{tabular}{lc}
$\begin{array}{l}\text { Table } 2 \text { Health status and utilisation among subjects } \\
\text { with COPD and past employment }\end{array}$ \\
\hline
\end{tabular}


Table 3 Occupational factors and smoking at baseline as predictors of health status and quality of life at follow up

\begin{tabular}{|c|c|c|c|c|c|c|c|}
\hline \multicolumn{2}{|l|}{ Risk factors at baseline } & \multicolumn{6}{|c|}{ Health status and quality of life at follow up } \\
\hline \multirow[b]{2}{*}{ Risk factor } & \multirow{2}{*}{$\begin{array}{l}\text { Frequency } \\
\mathrm{n}(\%)\end{array}$} & \multicolumn{2}{|c|}{$\begin{array}{l}\text { SF-12 physical component } \\
\text { score }\end{array}$} & \multicolumn{2}{|c|}{$\begin{array}{l}\text { SF-12 mental component } \\
\text { score }\end{array}$} & \multicolumn{2}{|c|}{ Respiratory quality of life score } \\
\hline & & Mean (SE) & $\mathrm{p}$ value & Mean (SE) & $\mathrm{p}$ value & Mean (SE) & $\mathrm{p}$ value \\
\hline \multicolumn{8}{|l|}{ Occupational risk factors } \\
\hline No disability or exposure (referent) & $86(37 \%)$ & $41.1(1.2)$ & NA & $47.8(1.0)$ & NA & $5.0(0.5)$ & NA \\
\hline VGDF exposure, no work disability & $90(38 \%)$ & $37.1(1.2)$ & 0.02 & $47.2(1.0)$ & 0.66 & $6.8(0.5)$ & 0.01 \\
\hline Work disability, no exposure & $20(9 \%)$ & $30.7(2.5)$ & $<0.001$ & $45.7(2.1)$ & 0.36 & $10.3(1.0)$ & $<0.001$ \\
\hline Work disability and VGDF exposure & $38(16 \%)$ & $29.1(1.9)$ & $<0.001$ & $47.0(1.5)$ & 0.68 & $12.0(0.8)$ & $<0.001$ \\
\hline \multicolumn{8}{|l|}{ Cigarette smoking status } \\
\hline Never (referent) & 42 (18\%) & $37.5(1.8)$ & NA & $49.3(1.5)$ & NA & $8.2(0.8)$ & NA \\
\hline Former & $117(50 \%)$ & $32.1(1.1)$ & 0.01 & $48.4(0.9)$ & 0.6 & $8.6(0.4)$ & 0.57 \\
\hline Current & 75 (32\%) & $33.9(1.4)$ & 0.09 & $43.1(1.1)$ & 0.001 & $8.7(0.6)$ & 0.52 \\
\hline
\end{tabular}

SE, standard error; VGDF, exposure to vapours, gas, dust, or fumes; work disability, respiratory related work disability.

Multivariate model includes the variables shown as well as smoking status, age by category, gender, and race (see table 1 for variable definitions).

Higher SF-12 scores reflect better health status; higher quality of life scores reflect poorer quality of life.

SF-12 PCS $(\beta=-1.2(2.4) ; p=0.61)$ or QOL $(\beta=1.6(1.2)$; $\mathrm{p}=0.21$ ).

Table 4 shows the associations of VGDF exposure and respiratory related work disability with restricted activity days and healthcare utilisation. In the single effects models, VGDF exposure was not associated with risk of frequent (everyday) restricted activity days breathing (OR 1.2; 95\% CI 0.6 to 2.7 ), emergency department (ED) visits (OR 1.6; $95 \%$ CI 0.7 to 3.5 ), or hospitalisations (OR $1.8 ; 95 \%$ CI 0.7 to 4.7 ). The effect of VGDF exposure in the absence of respiratory related work disability (that is, from the combined models) was essentially the same as in the single effects models.

By contrast, respiratory related work disability was associated with an increased risk of restricted activity days (OR 3.6; 95\% CI 1.7 to 7.9 ), ED visits (OR 3.0; 95\% CI 1.4 to 6.6), and hospitalisations (OR 4.5; 95\% CI 1.7 to 11.8 ), when VGDF exposure was not included in the model. In the combined models, the association of work disability with restricted activity and hospitalisation increased slightly, but the association with ED visits decreased sharply (OR 1.2; 95\% CI 0.3 to 5.0 ).

Simultaneous exposure to VGDF and respiratory related work disability was associated with a greater risk of restricted activity days (OR 3.8; 95\% CI 1.4 to 10.1), ED visits (OR 3.9; 95\% CI 1.4 to 10.5), and hospitalisation (OR 7.6; 95\% CI 1.8 to 32.1). Cigarette smoking status was not a statistically significant, independent predictor of any of these three outcomes after taking into account the occupational factors above (data not shown).

Table 5 shows an analysis limited to 159 subjects without the highest category of respiratory symptoms at baseline (dyspnoea on exertion at own pace or troubled breathing every day; see table 2). Combined VGDF and respiratory related work disability was related to decline in respiratory status over follow up (OR 4.5; 95\% CI 1.3 to 16.0). Among 186 subjects who had reported neither respiratory related ED visit nor hospitalisation at baseline (table 5), incident healthcare utilisation was related to combined VGDF and respiratory related work disability (OR 6.9; 95\% CI 2.0 to 24.0). Neither VGDF nor respiratory related work disability alone was a statistically significant predictor of either declining respiratory status or incident healthcare utilisation in these models.

Substituting occupational risk based on the job exposure matrix rather than assessed by self report of VGDF exposure did not substantively impact this pattern of results. For decline in respiratory status, combined intermediate to high risk occupations by job exposure matrix and respiratory work disability were associated with an OR of $4.5(p=0.03)$; for incident ED visit or hospital admission the same combined risks were associated with an OR of $3.9(p=0.02)$. The risk factors alone were not associated with statistically significant ORs.

In multiple linear regression analysis excluding chronic bronchitis (remaining $n=122$ ), combined VGDF and respiratory related work disability were related to lower SF-12 PCS $(\beta=-8.7$ (SE 2.6); $p<0.001)$ and poorer QOL $(\beta=5.9$ (SE $1.2) ; \mathrm{p}<0.001)$. Respiratory related work disability alone was also predictive of both SF-12 PCS $(\beta=-10.8$ (SE 3.3); $\mathrm{p}=0.002)$ and poorer QOL $(\beta=5.3$ (SE 1.4); $\mathrm{p}<0.001)$, while VGDF exposure was not a statistically significant predictor of either outcome in the same models.

In multiple logistic regression analysis excluding chronic bronchitis (remaining $\mathrm{n}=91$ ), incident ED visit or hospitalisation remained associated with combined VGDF exposure and respiratory related work disability $(\mathrm{OR}=3.3 ; 95 \%$ CI 0.8

Table 4 Occupational factors as predictors of limitation and healthcare utilisation

\begin{tabular}{|c|c|c|c|c|c|c|}
\hline \multirow[b]{3}{*}{ Occupational risk factors at baseline } & \multicolumn{6}{|c|}{ Limitation and utilisation at follow up } \\
\hline & \multicolumn{2}{|l|}{ Restricted activity } & \multicolumn{2}{|c|}{$\geqslant 1$ emergency dept visits } & \multicolumn{2}{|l|}{$\geqslant 1$ hospitalisation } \\
\hline & $\begin{array}{l}\text { Individual } \\
\text { exposure } \\
\text { OR (95\% Cl) }\end{array}$ & $\begin{array}{l}\text { Combined } \\
\text { exposure } \\
\text { OR }(95 \% \mathrm{CI})\end{array}$ & $\begin{array}{l}\text { Individual } \\
\text { exposure } \\
\text { OR }(95 \% \mathrm{Cl})\end{array}$ & $\begin{array}{l}\text { Combined } \\
\text { exposure } \\
\text { OR }(95 \% \mathrm{Cl})\end{array}$ & $\begin{array}{l}\text { Individual } \\
\text { exposure } \\
\text { OR }(95 \% \mathrm{Cl})\end{array}$ & $\begin{array}{l}\text { Combined } \\
\text { exposure } \\
\text { OR }(95 \% \mathrm{CI})\end{array}$ \\
\hline No disability or exposure & - & - & - & - & - & - \\
\hline VGDF exposure & $1.2(0.6$ to 2.7$)$ & $1.1(0.4$ to 3.1$)$ & $1.6(0.7$ to 3.5$)$ & $0.9(0.3$ to 2.4$)$ & $1.8(0.7$ to 4.7$)$ & $2.1(0.5$ to 8.4$)$ \\
\hline Work disability & $3.6(1.7$ to 7.9$)$ & $3.9(1.1$ to 13.6$)$ & $3.0(1.4$ to 6.6$)$ & $1.2(0.3$ to 5.0$)$ & 4.5 (1.7 to 11.8$)$ & 6.3 (1.2 to 33.0$)$ \\
\hline Work disability and VGDF exposure* & - & $3.8(1.4$ to 10.1$)$ & - & $3.9(1.4$ to 10.5$)$ & - & $7.6(1.8$ to 32.1$)$ \\
\hline
\end{tabular}

Multivariate model includes the variables shown, as well as smoking status, age by category, gender, and race (see table 1 for variable definitions and table 3 for definition and frequencies of risk factors). In combined model, odds ratios are presented for the effect of one risk factor in the absence of the other. *The simultaneous presence of both risk factors. 
Table 5 Occupational factors as predictors of decline in health status or increased healthcare utilisation

\begin{tabular}{|c|c|c|}
\hline $\begin{array}{l}\text { Employment } \\
\text { measures }\end{array}$ & $\begin{array}{l}\text { Decline in } \\
\text { respiratory } \\
\text { status } \\
52 \text { of } 159 \\
\text { subjects } \\
\text { OR }(95 \% \mathrm{CI})\end{array}$ & $\begin{array}{l}\text { New ED or } \\
\text { hospital } \\
\text { admission } \\
27 \text { of } 186 \\
\text { subjects } \\
\text { OR }(95 \% \mathrm{CI})\end{array}$ \\
\hline \multirow{4}{*}{$\begin{array}{l}\text { No disability or } \\
\text { exposure (referent) } \\
\text { VGDF exposure, } \\
\text { no work disability } \\
\text { Work disability, } \\
\text { no VGDF exposure } \\
\text { Work disability and } \\
\text { VGDF exposure }\end{array}$} & - & - \\
\hline & 1.7 (0.8 to 2.7$)$ & $1.2(0.4$ to 3.5$)$ \\
\hline & $1.9(0.4$ to 8.2$)$ & $1.5(0.3$ to 8.2$)$ \\
\hline & $4.5(1.3$ to 16.0$)$ & $6.9(2.0$ to 24.0$)$ \\
\hline
\end{tabular}

Multivariate model includes the variables shown as well as smoking status, age by category, gender, and race (see table 1 for variable definitions and table 3 for definition of risk factors).

Decline in respiratory status defined as increased symptoms of dyspnoea on exertion or shortness of breath at rest over the two weeks preceding the follow up interview, in comparison to the two weeks preceding the baseline interview. The model excludes 75 individuals who reported serious symptoms at baseline.

New ED or hospital admission defined as report of an emergency room visit or hospitalisation in the 12 months prior to follow up interview, but not in the baseline interview. This model excludes 19 individuals with ED or hospital admissions in the 12 months preceding the baseline interview.

to 13.2), although the widened confidence interval did not exclude no effect. Neither isolated VGDF (OR 0.3; 95\% CI 0.1 to 1.6 ) nor respiratory related work disability (OR 0.9; $95 \%$ CI 0.1 to 5.9) were associated with incident ED visit or hospitalisation.

\section{DISCUSSION}

Morbidity among persons with COPD is considerable and is likely to be multifactorial in nature. ${ }^{23} 24$ Underlying disease severity is presumed to be a major determinant of health outcomes in COPD. To the extent that cigarette smoking is the most important factor affecting severity, some of the variability in morbidity may be explained by this factor. It is clear from studies of asthma as well as other chronic health conditions; however, that disease severity is not the sole explanatory factor for the variability that may be observed in such health outcomes as subjective symptoms, reported activity limitations, or healthcare utilisation.

The findings of this study point to occupational factors as one set of characteristics that may be driving outcomes in COPD. We found that these factors were associated with poorer general health status, worse respiratory specific QOL, and substantially increased risk of restricted activity, emergency department visits, and hospitalisation for lung disease.

The potential pathways by which occupational factors could be associated with poorer health outcomes are likely to be complex. Material of occupational origin retained in the lung, particularly dusts, may exert ongoing effects in the context of progressive disease. Metal fumes such as cadmium or vanadium have been implicated in emphysema and chronic bronchitis, while organic dusts have been linked to chronic airflow obstruction, but it is unclear whether the rate of disease progression in such cases differs from disease attributable to smoking. ${ }^{3}$

We found that exposure to VGDF was associated with respiratory related work disability. In turn, we also found that respiratory related work disability was a powerful predictor of the adverse COPD health outcomes of study interest. For several of these outcomes, either VGDF or respiratory related work disability were independently associated with these outcomes even after taking into account the presence of both risk factors combined. These associations support a hypothetical model in which exposure to VGDF may lead to respiratory related work disability (itself a marker for risk of adverse outcomes), VGDF exposure may be a risk factor for adverse outcomes independently of work disability, and work disability may carry risk without the presence of VGDF exposure.

Respiratory related work disability may be a particularly potent marker of risk, since it reflects disease onset and progression at an early enough age to affect labour force participation. For several of the outcomes we examined there was little to no step up in effect when VGDF exposure was also present along with respiratory related work disability. Nonetheless, the combined presence of respiratory related work disability and exposure to VGDF showed the strongest and most consistent association with the outcomes we studied in this analysis.

Although our study was prospective, effects of selection, potential recall bias, and misclassification may still be operative. Because we restricted the analysis to persons with past labour force participation and used longest job held, not simply current or last employment, "healthy worker" effects should not be prominent in this cohort. Reporting of exposure to VGDF may be driven in part by recall effects. We have previously shown that such reported exposure corresponds fairly well to exposure assessment made by matching reported occupation and industry to an imputed likelihood of exposure. ${ }^{47}$ We retested key models using this job exposure matrix which yielded a similar pattern of estimated effects. Although we used a standard epidemiological definition of COPD based on reported physician diagnosis of conditions, some misclassification is possible. ${ }^{12}{ }^{25} \mathrm{We}$ did not have access to medical records for validation of diagnoses and we did not perform pulmonary function testing in the cohort. However, excluding subjects with chronic bronchitis alone did not substantively alter the main analytical findings.

We found that occupational co-factors among persons with COPD are linked to poorer health status and increased healthcare utilisation. It will be important to document whether these trends in morbidity continue over time with disease progression and whether the same risk factors predict mortality. A recent study estimated that more than 14000 deaths due to occupationally related COPD occur each year in the USA, assuming that disease severity is equivalent between occupational and non-occupational cases. ${ }^{26}$ Should work related COPD be shown to be more severe, this mortality estimate may prove to be too low.

\section{Authors' affiliations}

P D Blanc, M D Eisner, J R Balmes, The Division of Occupational and Environmental Medicine, Department of Medicine, University of California San Francisco, San Francisco, California, USA

L Trupin, E H Yelin, P P Katz, The Division of Rheumatology, Department of Medicine, University of California San Francisco, San Francisco, California, USA

Supported by: NIH-NHLBI HL607438

\section{REFERENCES}

1 Becklake M. Occupational exposures: evidence for a causal association with chronic obstructive pulmonary disease. Am Rev Respir Dis 1989;140:S85-91. 2 Viegi G, Di Pede C. Chronic obstructive lung diseases and occupational exposure. Curr Opin Allergy Clin Immunol 2002;2:115-21.

3 Balmes J, Becklake M, Blanc P, et al. American Thoracic Society statement: occupational contribution to the burden of airway disease. Am J Respir Crit Care Med 2003; 167:787-97.

4 Blanc PD, Burney P, Janson C, et al. The prevalence and predictors of respiratory-related work limitation and occupational disability in an international study. Chest, In press.

5 Blanc PD. Characterizing the occupational impact of asthma. In: Weiss KB, Buist AS, Sullivan SD, eds. Asthma's impact on society: the social and 
economic burden. Lung biology in health and disease. New York: Marcel Dekker, 1999:55-75.

6 Liss GM, Tarlo SM, Macfarlane Y, et al. Hospitalization among workers compensated for occupational asthma. Am J Respir Crit Care Med 2000;162:112-18.

7 Trupin L, Earnest G, San Pedro M, et al. The occupational burden of chronic obstruction pulmonary disease. Eur Respir J 2003;22:462-9

$8 \mathrm{Kim}$ J. Atlas of respiratory disease mortality, United States: 1982-1993. Cincinnati, OH: Department of Health and Human Services, National Institute for Occupational Safety and Health, 1998:1-23.

9 US Bureau of the Census. Industry and occupation classification system. Washington, DC: US Department of Commerce, 2000.

10 United Medical and Dental Schools of Guy's and St Thomas' Hospitals, Department of Public Health Medicine. Protocol for the European Community Respiratory Health Survey. London: UMDS St Thomas's Campus, 1993.

11 Blanc P, Ellbjar S, Janson C, et al. Asthma-related work disability in Sweden. The impact of workplace exposures. Am J Respir Crit Care Med 1999; 160:2028-33.

12 Mannino D, Gagnon R, Petty T, et al. Obstructive lung disease and low lung function in adults in the United States. Arch Int Med 2000;160:1683-9.

13 Kovar M, Poe G. The National Health Interview Survey: design 1973-84 and procedures 1975-83. DHHS publication no. PHS 85-1320. Hyattsville, MD: US Dept of Health and Human Services, Public Health Service, National Center for Health Statistics, 1985.

14 Ware JE, Sherbourne CD. The MOS 36-item short-form health survey (SF-36). I. Conceptual framework and item selection. Med Care 1992;30:473-83

15 Ware JE, Kosinski M, Keller SD. SF-12: How to score the SF-12 Physical and Mental Health Summary score, 2nd edn. Boston, MA: The Health Institute, New England Medical Center, 1995.
16 Mirvitles M, Alvarez-Sala JL, Lamarca R, et al. Treatment and quality of life in patients with chronic obstructive pulmonary disease. Qual Life Res 2002;11:329-38

17 Scherer TA, Spengler CM, Owassapian D, et al. Respiratory muscle endurance training in chronic obstructive pulmonary disease. Am J Respir Crit Care Med 2000; 162:1709-14

18 Kosinski M, Bayliss M, Bjorner JB, et al. Improving estimates of the SF-36 Health Survey scores for respondents with missing data. Medical Outcomes Trust Monitor 2000;5(1):8-10.

19 Ware JE, Kosinski M, Turner-Bowker DM, et al. How to score version 2 of the SF-12 Health Survey. Lincoln, RI: QualityMetric Incorporated, 2002.

20 Barley EA, Quirk FH, Jones PW. Asthma health status measurement in clinical practice: validity of a new short and simple instrument. Respir Med 1998;92:1207-14

21 Hajiro T, Nishimura K, Jones PW, et al. A novel, short, and simple questionnaire to measure health-related quality of life in patients with chronic obstructive pulmonary disease. Am J Respir Crit Care Med 1999;159:1874-8

22 Blanc PD, Eisner MD, Earnest G, et al. Quality of life in adult asthma measured by different instruments: performance characteristics [abstract]. Chest 2001; 120:140s.

23 US Department of Health and Human Services. The health consequences of smoking: chronic obstructive lung disease. A report of the Surgeon General. Rockville, MD: US Government Printing Office, 1984.

24 Anto J, Vermeire P, Vestbo J, et al. Epidemiology of chronic obstructive pulmonary disease. Eur Respir J 2001;17:982-94.

25 Straus S, McAlister F, Sackett D, et al. Accuracy of history, wheezing, and forced expiratory time in the diagnosis of chronic obstructive pulmonary disease. J Gen Intern Med 2002;17:684-8.

26 Steenland K, Burnett C, Lalich N, et al. Dying for work: the magnitude of US mortality from selected causes of death associated with occupation. Am J Ind Med 2003;43:461-82.

\section{Call for papers}

10th European Forum on Quality Improvement in Health Care

13-15 April 2005, ExCel, Docklands, London

For further information on how to submit your paper please go to:

http://www.quality.bmipg.com 